\title{
Different Effects of Bile and Sodium Taurocholate on Mucosal Calcium Accumulation and Calcium Absorption in Rats
}

\author{
Liangchai LIMLOMWONGSE and Nateetip KRISHNAMRA \\ Department of Physiology, Faculty of Science, Mahidol University, \\ Rama VI Road, Bangkok 10400, Thailand
}

(Received November 24, 1988)

\begin{abstract}
Summary To demonstrate different effects of bile and $\mathrm{Na}$ taurocholate on calcium absorption, in vivo studies and in situ intestinal loop experiments were performed in intact rats. Only bile (collected from donor rats), but not $15 \mathrm{~mm} \mathrm{Na}$ taurocholate, significantly increased the jejunal mucosa calcium and ${ }^{45} \mathrm{Ca}$ contents after an intragastric administration of test solution containing $7.5 \mathrm{~mm} \mathrm{CaCl} 2+{ }^{45} \mathrm{Ca}$. However, plasma radioactivity which represented lumen to plasma calcium transport was increased by $\mathrm{Na}$ taurocholate but not bile, suggesting that both agents enhanced calcium transport across the brush border membrane but in the presence of bile some calcium remained in the mucosal cells. Results from the in situ studies supported the above findings. It was shown that bile and $\mathrm{Na}$ taurocholate enhanced the calcium transport from the lumen. However, net absorption was unchanged due to concurrent increase in the efflux of calcium.
\end{abstract}

Key Words bile, bile acids, calcium absorption, calcium transport, sodium taurocholate

It has been shown that normal biliary secretion had some influence on intestinal calcium absorption and that certain dihydroxy bile salts enhanced calcium uptake(1-3). However, there has been no report on the effect of sodium taurocholate, the main bile salt in rat(4-6), on calcium absorption. Moreover, experiments with erythrocytes demonstrated that bile salts were damaging to membrane $(7,8)$, and interestingly, the damaging effects were attenuated by the presence of phospholipids in bile (9). This evidence suggested that bile salts and bile may exert different effects on the calcium absorption.

Calcium malabsorption has been reported in some patients with primary biliary cirrhosis. Although vitamin D deficiency is well documented in many of these patients (10-13), the relationship between intestinal calcium malabsorption and the vitamin D status in these patients is controversial $(10,13-16)$. It is possible that besides vitamin $\mathrm{D}$, other factors, e.g., cholestasis, may also be a cause of calcium 
malabsorption.

The present study thus aimed to evaluate the effects of bile salt and bile on the in vivo intestinal calcium absorption, mucosal calcium uptake by the duodenal and jejunal segments of the small intestine, and calcium fluxes across the in situ intestinal loops.

\section{MATERIALS AND METHODS}

Animal preparation. Female Wistar rats weighing $180-200 \mathrm{~g}$, fed on standard laboratory chow (F. F. Zuellig, Thailand), were used as experimental animals. Eighteen hours before the experiment, the rats were anesthetized with ether; through an abdominal incision, the hepatic bile duct was tied off. The wound was closed and the animals were fasted overnight with access to water. It has been found that ligation of hepatic bile duct $18 \mathrm{~h}$ prior to the experiment reduced the intestinal luminal content of bile salts to a negligible amount (data not shown).

In vivo study. On the experimental day, the rats with ligated bile duct were anesthetized with sodium pentobarbital ( $50 \mathrm{mg} / \mathrm{kg}$ body weight, i.p). Constant body temperature of $37^{\circ} \mathrm{C}$ was maintained by an overhead lamp throughout the experiment. After tracheostomy, the femoral artery and vein were cannulated for blood collection and fluid administration, respectively. At zero min, test solution was administered intragastrically via a stomach tube. Ten, 30, or $60 \mathrm{~min}$ later, a midline incision was made to expose the small intestine. The duodenal $(0-5 \mathrm{~cm}$ distal to pyloric sphincter) and jejunal $(10-15 \mathrm{~cm}$ distal to pyloric sphincter) segments were removed. Each segment was cleaned for the adherent fat, cut longitudinally, and rinsed once in normal saline before being blotted dry. By using a glass slide, the mucosa was scraped, weighed, and placed in a centrifuge tube and dissolved in $0.4 \mathrm{ml}$ of $0.5 \mathrm{~N} \mathrm{NaOH}$ at $80^{\circ} \mathrm{C}$ for $45 \mathrm{~min}$. After centrifugation the supernatant was analyzed for total calcium concentration by atomic absorption spectrophotometry (Varian 575) and ${ }^{45} \mathrm{Ca}$ (Radiochemical Centre, Amersham, U.K.; specific activity = $2.1 \mathrm{mCi} / \mathrm{ml}, 78 \mathrm{MBg} / \mathrm{ml}$ ) by the standard liquid scintillation spectrophotometry (LKB 1219, Rackbeta). The determination of mucosal ${ }^{40} \mathrm{Ca}$ and ${ }^{45} \mathrm{Ca}$ contents was done at the luminal calcium concentrations of 7.5 and $0.5 \mathrm{~mm}$. The animals were therefore divided randomly into 6 groups, which received the test solutions as described below.

A. Luminal calcium concentration $=7.5 \mathrm{~mm}$

Group I: $1 \mathrm{ml}$ of $0.9 \% \mathrm{NaCl}+1 \mathrm{ml}$ of $15 \mathrm{~mm} \mathrm{CaCl}+2 \mu \mathrm{Ci}^{45} \mathrm{CaCl}_{2}$

Group II: $1 \mathrm{ml}$ of $30 \mathrm{~mm} \mathrm{Na}$ taurocholate dissolved in $0.9 \% \mathrm{NaCl}+1 \mathrm{ml}$ of $15 \mathrm{mM} \mathrm{CaCl}_{2}+2 \mu \mathrm{Ci}^{45} \mathrm{CaCl}_{2}$

Group III: $1 \mathrm{ml}$ of bile $+1 \mathrm{ml}$ of $15 \mathrm{mM} \mathrm{CaCl}_{2}+2 \mu \mathrm{Ci}^{45} \mathrm{CaCl}_{2}$

B. Luminal calcium concentration $=0.5 \mathrm{mM}$

Group IV: $1 \mathrm{ml}$ of $0.9 \% \mathrm{NaCl}+1 \mathrm{ml}$ of $1.0 \mathrm{~mm} \mathrm{CaCl} 2+2 \mu \mathrm{Ci}^{45} \mathrm{CaCl}_{2}$

Group $\mathrm{V}: 1 \mathrm{ml}$ of $30 \mathrm{~mm} \mathrm{Na}$ taurocholate dissolved in $0.9 \% \mathrm{NaCl}+1 \mathrm{ml}$ of $1.0 \mathrm{~mm} \mathrm{CaCl}_{2}+2 \mu \mathrm{Ci}^{45} \mathrm{CaCl}_{2}$ 
Group VI: $1 \mathrm{ml}$ of bile $+1 \mathrm{ml}$ of $1.0 \mathrm{~mm} \mathrm{CaCl}_{2}+2 \mu \mathrm{Ci}^{45} \mathrm{CaCl}_{2}$

As mentioned before, each group was studied at 10, 30, and $60 \mathrm{~min}$ after an intragastric administration of test solution. Blood collections at 15 and $60 \mathrm{~min}$ for plasma ${ }^{45} \mathrm{Ca}$ determination were performed only in the groups studied at $60 \mathrm{~min}$. Bile used was freshly collected from normal rats of the same range of body weight under sodium pentobarbital anesthesia from cannulated hepatic bile duct. The bile salt concentration in collected bile determined enzymatically by $3 \alpha$ hydroxy steroid dehydrogenase (17) averaged $22.0 \pm 2.4 \mathrm{~mm}$. Bile calcium concentration was $1.50 \pm 0.06 \mathrm{~mm}$.

In situ study. Under sodium pentobarbital anesthesia, tracheostomy was performed. The in situ $5 \mathrm{~cm}$ duodenal and jejunal loops were prepared as previously described (18). Briefly, through the midline abdominal incision, the distal end of the bile duct and pyloric sphincter were ligated. The duodenal loop was prepared by making a ligation $5 \mathrm{~cm}$ distal to the pyloric ligation. The jejunal loop was prepared by making ligations at $10-15 \mathrm{~cm}$ distal to the pyloric ligation. After the loops were washed with $0.9 \% \mathrm{NaCl}$, they were filled with $0.5 \mathrm{ml}$ of test solution containing (in mм) $\mathrm{NaCl} 125, \mathrm{NaHCO}_{3} 25, \mathrm{KCl} 4.7, \mathrm{CaCl}_{2} 0.9$, and $\mathrm{MgSO}_{4} 1.2$, and approximately $2 \mu \mathrm{Ci} / \mathrm{ml}^{45} \mathrm{CaCl}_{2}$. The test solution was adjusted to $\mathrm{pH} 7.2$. The abdominal opening was closed with sutures and the body temperature was maintained at $37^{\circ} \mathrm{C}$ with an overhead heating lamp.

After 30-min incubation, the intestinal loops were removed and their contents were determined for volume, calcium, and ${ }^{45} \mathrm{Ca}$ concentrations. The calcium influx and efflux were calculated according to the following equations modified from Wasserman et al.(19):

$$
\begin{aligned}
& \text { Net absorption }=\left(V_{\mathrm{i}}\right)\left({ }^{40} \mathrm{Ca}_{\mathrm{i}}\right)-\left(V_{\mathrm{f}}\right)\left({ }^{40} \mathrm{Ca}_{\mathrm{f}}\right) / L \\
& \mathrm{Ca}_{\text {Inf }}=\frac{\left(V_{\mathrm{i}}\right)\left({ }^{45} \mathrm{Ca}_{\mathrm{i}}\right)-\left(V_{\mathrm{f}}\right)\left({ }^{45} \mathrm{Ca}_{\mathrm{f}}\right)}{\left({ }^{45} \mathrm{Ca}_{\mathrm{i}} /{ }^{40} \mathrm{Ca}_{\mathrm{i}}+{ }^{45} \mathrm{Ca}_{\mathrm{f}} /{ }^{40} \mathrm{Ca}_{\mathrm{f}}\right) 2 L} \\
& \mathrm{Ca}_{\text {Eff }}=\mathrm{Ca}_{\text {Inf }} \text { - net absorption }
\end{aligned}
$$

where $V$ is the volume of test solution; ${ }^{40} \mathrm{Ca},{ }^{40} \mathrm{Ca}$ concentration, ${ }^{45} \mathrm{Ca},{ }^{45} \mathrm{Ca}$ concentration; $L$, the length of intestinal loop; $\mathrm{Ca}_{\text {Inf }}$ calcium movement from lumen; $\mathrm{Ca}_{\text {eff }}$, calcium movement into the lumen; and subscripts $\mathrm{i}$ and $\mathrm{f}$ are initial and final, respectively. It is assumed that the reentry of ${ }^{45} \mathrm{Ca}$ into the lumen solution was negligible $(19,20)$. According to the original equation for calculating the calcium fluxes (19), the amount of calcium lost from the luminal solution was represented by $\mathrm{Ca}_{\mathrm{L}-\mathrm{P}}$ (lumen to plasma flux of calcium). The $\mathrm{Ca}_{\mathrm{P}-\mathrm{L}}$ (plasma to lumen flux of calcium) was then calculated from the difference between net absorption and the $\mathrm{Ca}_{\text {L-P. }}$. In the original equation, $\mathrm{Ca}_{\mathrm{L}-\mathrm{P}}$ was calculated by subtracting the final ${ }^{45} \mathrm{Ca}$ content from the initial ${ }^{45} \mathrm{Ca}$ content in the lumen. However, we felt that the $\mathrm{Ca}_{\mathrm{L}-\mathrm{P}}$ did not necessarily represent the calcium flux from lumen to plasma, but actually represented the amount of calcium transported out of the lumen. This amount of calcium may or may not reach the plasma compartment. Similarly, the $\mathrm{Ca}_{\mathrm{P}-\mathrm{L}} \mathrm{did}$ 
not necessarily represent the calcium flux from the plasma to the lumen, but rather indicated the flux of calcium into the lumen from the plasma or the epithelial cells. We therefore made a slight modification of the equation and used the terms $\mathrm{Ca}_{\text {Inf }}$ and $\mathrm{Ca}_{\mathrm{Eff}}$ to indicate the movement of calcium out of and into the lumen, respectively.

The rats were divided randomly into 3 groups; the duodenal and jejunal loops were filled with one of the following test solutions:

Group I: $0.5 \mathrm{ml}$ of solution $\mathrm{A}+0.5 \mathrm{ml}$ of $0.9 \% \mathrm{NaCl}+2 \mu \mathrm{Ci}{ }^{45} \mathrm{CaCl}_{2}$

Group II: $0.5 \mathrm{ml}$ of solution A $+0.5 \mathrm{ml}$ of $30 \mathrm{~mm} \mathrm{Na}$ taurocholate dissolved in $0.9 \% \mathrm{NaCl}+2 \mu \mathrm{Ci}^{45} \mathrm{CaCl}_{2}$

Group III: $0.5 \mathrm{ml}$ of solution $\mathrm{A}+0.5 \mathrm{ml}$ of bile $+2 \mu \mathrm{Ci}{ }^{45} \mathrm{CaCl}_{2}$. Solution A contained (in $\mathrm{mM}$ ) $\mathrm{NaCl} 125, \mathrm{NaHCO}_{3} 25, \mathrm{KCl} 4.7, \mathrm{MgSO}_{4}$ 1.2, and $\mathrm{CaCl}_{2} 15$ ( $\mathrm{pH}$ 7.2). The solutions were prewarmed to $37^{\circ} \mathrm{C}$ before use.

All data were statistically computed as mean \pm SEM, and multiple comparisons of data were made by analysis of variance and Newman-Keuls test. A value of $p<0.05$ was considered significant.

\section{RESULTS}

As depicted in Table 1, in the groups which received the test solution containing $7.5 \mathrm{mM} \mathrm{CaCl}_{2}$, administration of $\mathrm{Na}$ taurocholate_- but not of bile-resulted in a significant increase in plasma ${ }^{45} \mathrm{Ca}$ concentration. However, neither $\mathrm{Na}$ taurocholate nor bile administration resulted in elevated plasma radioactivity when the animals were given $0.5 \mathrm{mM} \mathrm{CaCl}_{2}$ test solution (Table 2).

Figure 1 demonstrates the mucosal calcium and ${ }^{45} \mathrm{Ca}$ contents in the groups receiving test solutions containing $7.5 \mathrm{mM} \mathrm{CaCl}_{2}$. In contrast to the plasma ${ }^{45} \mathrm{Ca}$ data, the presence of bile in the luminal solution resulted in a significant increase in jejunal mucosal calcium content at all time intervals, while the duodenal mucosal content of calcium was significantly increased only at $60 \mathrm{~min}$. The same pattern was observed in the mucosal uptake of ${ }^{45} \mathrm{Ca}$. The presence of bile in the luminal solution in the duodenum and jejunum markedly increased the mucosal ${ }^{45} \mathrm{Ca}$ content, which

Table 1. Plasma ${ }^{45} \mathrm{Ca}$ concentration after intragastric administration of test solution containing $7.5 \mathrm{mM} \mathrm{CaCl}_{2}$ and ${ }^{45} \mathrm{Ca}$.

\begin{tabular}{llcc}
\hline \multirow{2}{*}{ Group } & & \multicolumn{2}{c}{ Plasma ${ }^{45} \mathrm{Ca}$ concentration $(\mathrm{cpm} / 0.1 \mathrm{ml})$} \\
\cline { 3 - 4 } & & $15 \mathrm{~min}$ & $60 \mathrm{~min}$ \\
\hline Saline control & $(n=6)$ & $570 \pm 40$ & $870 \pm 50$ \\
Na taurocholate & $(n=6)$ & $1,080 \pm 89^{* *}$ & $1,160 \pm 27^{* *}$ \\
Bile & $(n=6)$ & $720 \pm 140$ & $800 \pm 100$ \\
\hline
\end{tabular}

Mean \pm SEM, randomized design ANOVA and Newman-Keuls test were employed for comparison with saline control. ${ }^{* *} p<0.01$. 
Table 2. Plasma ${ }^{45} \mathrm{Ca}$ concentration after intragastric administration of test solution containing $0.5 \mathrm{~mm} \mathrm{CaCl}_{2}$ and ${ }^{45} \mathrm{Ca}$.

\begin{tabular}{llcc}
\hline \multirow{2}{*}{ Group } & & \multicolumn{2}{c}{ Plasma ${ }^{45} \mathrm{Ca}$ concentration $(\mathrm{cpm} / 0.1 \mathrm{ml})$} \\
\cline { 3 - 4 } & & $15 \mathrm{~min}$ & $60 \mathrm{~min}$ \\
\hline Saline control & $(n=6)$ & $246 \pm 38$ & $225 \pm 60$ \\
Na taurocholate & $(n=6)$ & $310 \pm 87$ & $228 \pm 58$ \\
Bile & $(n=6)$ & $348 \pm 87$ & $252 \pm 48$ \\
\hline
\end{tabular}

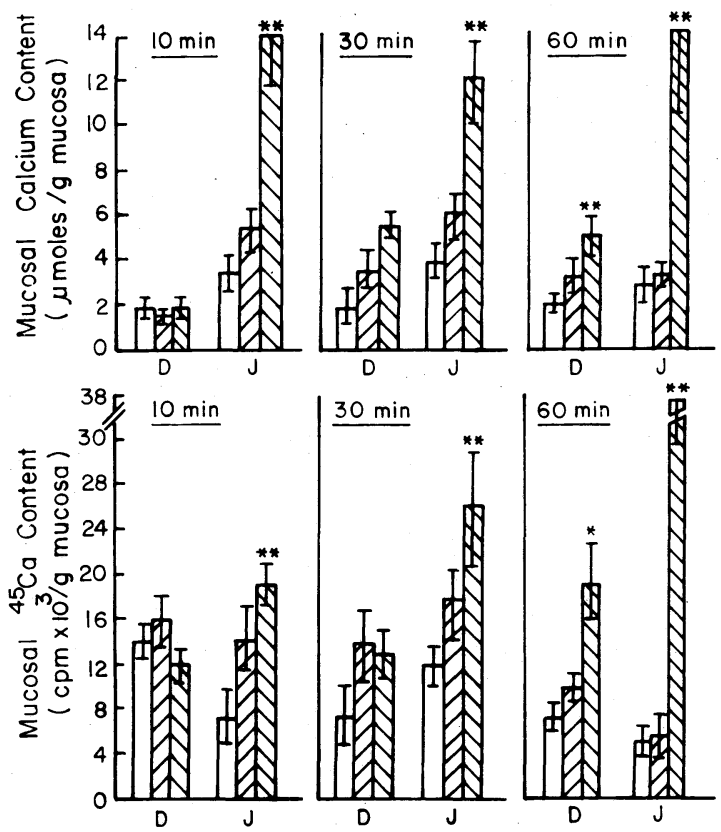

Fig. 1. The mucosal calcium content $\left(\mu \mathrm{mol} / \mathrm{g}\right.$ mucosa) and mucosal ${ }^{45} \mathrm{Ca}$ content $\left(\mathrm{cpm} \times 10^{3} / \mathrm{g}\right.$ mucosa) at 10,30 , and $60 \mathrm{~min}$ after intragastric administration of $2 \mathrm{ml}$ of $0.9 \% \mathrm{NaCl}(\square), \mathrm{Na}$ taurocholate ( $\square$ ), and bile ( $\square$ ) in test solution containing $7.5 \mathrm{mM} \mathrm{CaCl} 2$ and $2 \mu \mathrm{Ci}{ }^{45} \mathrm{Ca}$. (Mean $\pm \mathrm{SEM}$, randomized design ANOVA and Newman-Keuls test were used for comparison with saline control, ${ }^{*} p<0.05,{ }^{* *} p<0.01$.)

directly indicated the portion of calcium transported from the lumen. Figure 2 demonstrates the mucosal calcium and ${ }^{45} \mathrm{Ca}$ contents in the three groups which received test solutions containing $0.5 \mathrm{mM} \mathrm{CaCl}$. Luminal bile salt and bile were found to slightly but significantly increase the mucosal accumulation of calcium only in the jejunum at 10 and $30 \mathrm{~min}(p<0.05)$. The same pattern was again observed in the mucosal uptake of ${ }^{45} \mathrm{Ca}$. 


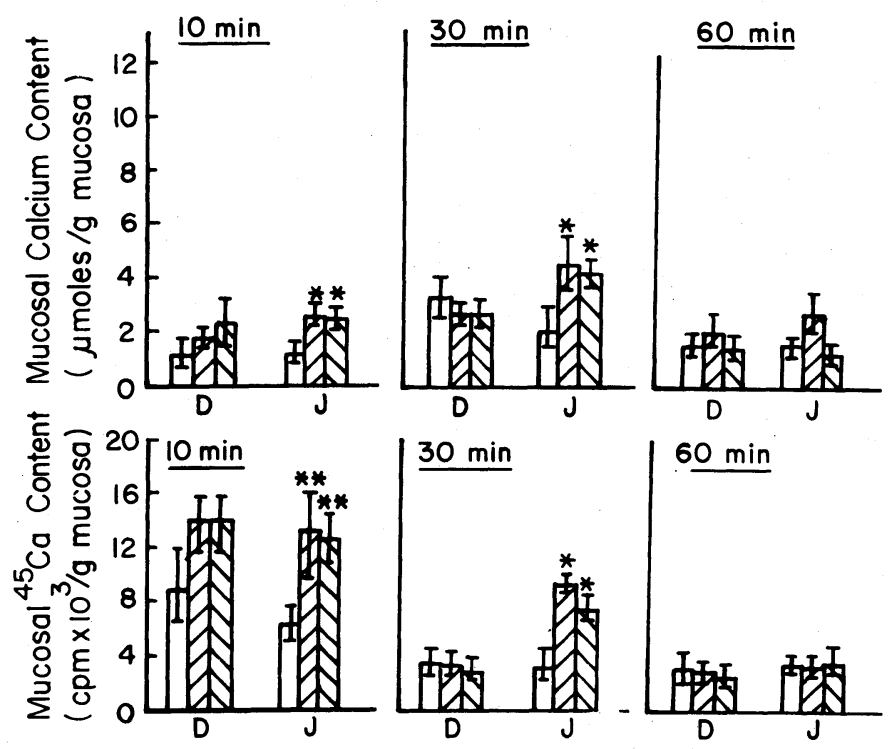

Fig. 2. The mucosal calcium content $\left(\mu \mathrm{mol} / \mathrm{g}\right.$ mucosa) and mucosal ${ }^{45} \mathrm{Ca}$ content $\left(\mathrm{cpm} \times 10^{3} / \mathrm{g}\right.$ mucosa) at 10,30 , and $60 \mathrm{~min}$ after intragastric administration of $2 \mathrm{ml}$ of $0.9 \% \mathrm{NaCl}(\square), \mathrm{Na}$ taurocholate ( שas), and bile ( $)$ ) in test solution containing $0.5 \mathrm{mM} \mathrm{CaCl}_{2}$ and $2 \mu \mathrm{Ci}{ }^{45} \mathrm{Ca}$. (Mean $\pm \mathrm{SEM}$, randomized design ANOVA and Newman-Keuls test were used for comparison with saline control, $* p<0.05,{ }^{* *} p<0.01$.)

The study of calcium fluxes were performed on the in situ duodenal and jejunal loops. As shown in Fig. 3, in the duodenum of control rat, $\mathrm{Ca}_{\text {Inf }}$ was greater than $\mathrm{Ca}_{\mathrm{Eff}}$, thus resulting in a net absorption of $0.82 \pm 0.10 \mu \mathrm{mol} / \mathrm{cm} / 30 \mathrm{~min}$. In the presence of a high calcium concentration as in the present study, there was virtually no movement of calcium in the jejunum, and the net calcium absorption entirely reflected the calcium influx. When compared to saline control, $\mathrm{Na}$ taurocholate was found to increase both the $\mathrm{Ca}_{\text {Inf }}$ and the $\mathrm{Ca}_{\text {Eff }}$ in the duodenum and jejunum. However, the net calcium absorption was not different from control. Similarly, the presence of bile in the lumen markedly increased both the $\mathrm{Ca}_{\text {Inf }}$ and $\mathrm{Ca}_{\mathrm{Eff}}$ in both the duodenum and jejunum. Despite such a marked increase in $\mathrm{Ca}_{\text {Inf }}$ in both the duodenum and jejunum of the group receiving bile, the $\mathrm{Ca}_{\mathrm{Eff}}$ was also enhanced so that the net calcium absorption was not different from that of control.

\section{DISCUSSION}

To compare the effects of bile and sodium taurocholate on calcium absorption, we determined the in vivo mucosal uptake of calcium and ${ }^{45} \mathrm{Ca}$ and the plasma ${ }^{45} \mathrm{Ca}$ concentration in the presence of high $(7.5 \mathrm{~mm})$ and low $(0.5 \mathrm{~mm})$ luminal calcium conditions. We did not include the ileum in the study because it has been shown that 


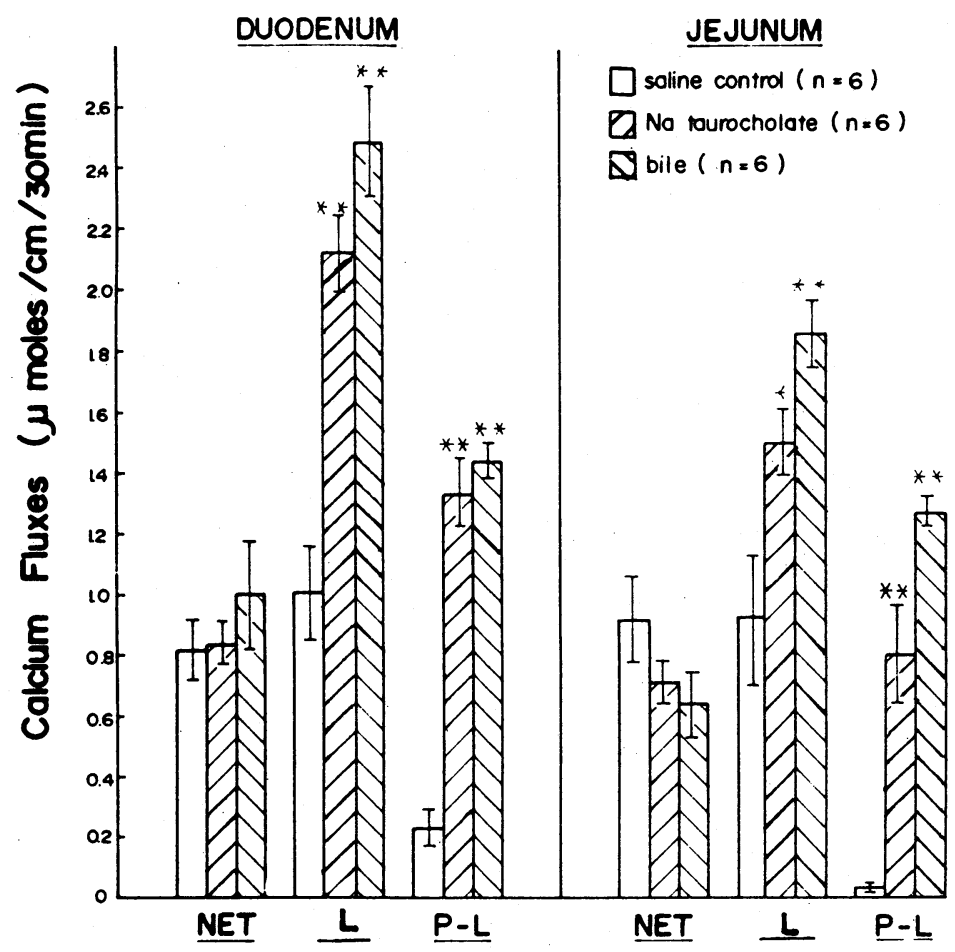

Fig. 3. Net absorption, removal from lumen (L), and plasma to lumen (P-L) fluxes of calcium in the in situ intestinal loops during 30-min incubation. Initial total calcium concentration was $7.5 \mathrm{mM}$. (Mean $\pm \mathrm{SEM}$, randomized design ANOVA and Newman-Keuls test were used for comparison with saline control. ${ }^{*} p<0.05$, ${ }^{* *} p<0.01$.)

most of the orally administered calcium in the range of concentrations used here was absorbed by the proximal and mid small intestine (21). The luminal calcium present in a more distal segment of the intestine was largely the secreted calcium. Moreover, due to the site of bile secretion, bile acids probably exert more effects in the proximal than in the distal small intestine.

Considering the effect of $\mathrm{Na}$ taurocholate and bile on the appearance of ${ }^{45} \mathrm{Ca}$ in plasma which represented calcium movement from lumen to plasma, as shown in Table 2, neither $\mathrm{Na}$ taurocholate nor bile was found to increase calcium absorption when the administered test solution contained calcium at a concentration $(0.5 \mathrm{~mm})$ lower than that in the ECF. The results indicated that the energy-dependent transport of calcium was probably not affected by both agents. This was confirmed by the data on duodenal mucosal calcium contents (Fig. 2), which showed no significant change in the presence of $\mathrm{Na}$ taurocholate or bile. Even in the presence of high luminal calcium concentration (Fig. 1), duodenal mucosal calcium content was not increased, confirming that the energy-dependent transport of calcium 
was not affected. In contrast, the mucosal calcium and ${ }^{45} \mathrm{Ca}$ contents in the jejunum were increased in the presence of bile and $\mathrm{Na}$ taurocholate. This partly reflected the type of calcium transport affected, i.e., passive or energy-independent transport, which is predominant in the jejunum (22). This marked increase in mucosal calcium may also be explained by a longer transit time in the jejunum as compared to the transit through the duodenum (23) in the in vivo condition.

Interestingly, a significant increase in plasma radioactivity which directly represented the lumen to plasma movement of calcium was seen only in the $\mathrm{Na}$ taurocholate-treated groups. Considering the mucosal calcium data and plasma ${ }^{45} \mathrm{Ca}$ data together, it seemed that $\mathrm{Na}$ taurocholate could enhance the calcium transport from lumen into the plasma without causing mucosal calcium accumulation. On the other hand, bile, despite having an enhancing effect on the mucosal calcium accumulation, did not result in an increase in the transfer of calcium into the plasma compartment. The difference between effects of $\mathrm{Na}$ taurocholate and bile may reside in the fact that bile contains some other constituents. Although taurocholate constitutes the main bile acid in rat, rat bile also contains other deoxybile acids such as chenodeoxycholate (6), the presence of which may be partly responsible for the different effects of bile and $\mathrm{Na}$ taurocholate on calcium absorption. This interpretation was supported by previous reports that certain dihydroxy bile acids act as calcium ionophores which enhance calcium transport across the brush border membrane into the mucosal cells $(2,3)$. Moreover, since deoxycholate has been reported to inhibit the activities of $\mathrm{Ca}-\mathrm{Mg}$-ATPase and $\mathrm{Ca}$ ATPase of the brush border membrane (24), it was possible that deoxycholate or other bile acids in bile may also inhibit the activity of Ca-ATPase or the Na-Ca exchange on the basolateral membrane. This would have explained the observed mucosal calcium accumulation in the presence of bile and not $\mathrm{Na}$ taurocholate.

At this point we would like to suggest that both bile and $\mathrm{Na}$ taurocholate enhanced the transport of calcium across the brush border membrane into the mucosa. However, Na taurocholate, but not bile, was found to enhance the transport of calcium into the plasma compartment, as evidenced by a significant increase in the plasma ${ }^{45} \mathrm{Ca}$ concentration. In the presence of bile, on the other hand, calcium transported across the brush border membrane appeared to remain in the mucosal cells, resulting in a significant increase in the mucosal ${ }^{45} \mathrm{Ca}$ content. The interpretation was further supported by our in situ findings which showed enhancing effects of $\mathrm{Na}$ taurocholate and bile on duodenal and jejunal calcium influx from lumen in the presence of calcium concentration of $7.5 \mathrm{mM}$.

In the in situ experiment, the effects of bile and $\mathrm{Na}$ taurocholate on calcium fluxes were found to be greater in the duodenum than in the jejunum, which was opposite to the results obtained from the in vivo experiment. This apparent discrepancy could be explained as follows. The proximal intestine, i.e., duodenum, is known to exhibit the highest rate of calcium absorption. However, under normal physiological condition, the transit time in the duodenum is faster than that in the more distal segment (23). As shown in Fig. 1, after an intragastric administration of 
labeled test solution, the mucosal ${ }^{45} \mathrm{Ca}$ content of the duodenum (Ca efflux) at $30 \mathrm{~min}$, showed a tendency to increase in both experimental groups but the changes were not significant. In contrast, when motility was inhibited and the mucosa was exposed to the test solution for $30 \mathrm{~min}$ as in the in situ preparation, a significant increase in calcium influx into the duodenal mucosa was evident in the presence of $\mathrm{Na}$ taurocholate and bile. Such increase in calcium influx was greater in the duodenum than in the jejunum.

Despite an increase in calcium influx, the calcium efflux from mucosa into the lumen was enhanced by both agents, thus resulting in no changes in the net absorption in both duodenum and jejunum. Evidence has indicated that there is a calcium secretory process in the rat duodenum $(25)$ and ileum $(25,26)$. Calcium secretion is mainly passive because the transepithelial potential difference is $4-5 \mathrm{mV}$, lumen negative. Since the luminal calcium concentration in our in situ experiment was $7.5 \mathrm{~mm}$, exceeding the blood ionized calcium concentration, this calcium concentration gradient may overcome the opposing electrical gradient and reduced calcium secretion. It has also been suggested that calcium secretion is largely paracellular since the apparent permeabilities of calcium secretion and secretion of mannitol or PEG (polyethylene glycol) were highly correlated $(27,28)$. The driving forces for calcium secretion, however, are not yet known. Bile salts are known to induce fluid secretion in all parts of the intestine. Mechanism of increased paracellular permeability by detergent effects, and altered levels of intracellular second messenger compound have been proposed as causes of net intestinal fluid secretion(29-31) but with paracellular pathway being predominant (31). However, the mechanism by which $\mathrm{Na}$ taurocholate or bile enhances calcium secretion remains to be identified.

The present data demonstrated that bile and $\mathrm{Na}$ taurocholate may affect intestinal calcium absorption differently, depending on the concentrations of bile acids, bile composition, and luminal calcium concentration. In the presence of high luminal calcium concentration, both bile and $\mathrm{Na}$ taurocholate were found to enhance calcium influx from the lumen but only $\mathrm{Na}$ taurocholate significantly increased the actual lumen to plasma flux of calcium. It was possible that different effects of $\mathrm{Na}$ taurocholate and bile on calcium absorption could be attributed to the presence of other active components of bile.

We thank Ms. W. Saengamnart for technical assistance and Ms. Kosoom Vongthai for typing the manuscript.

This work was supported in part by research grants from Mahidol University.

\section{REFERENCES}

1) Webling, D. D. A., and Holdsworth, E. S. (1966): Bile salts and calcium absorption. Biochem. J., 100, 652-660.

2) Maenz, D. D., and Forsyth, G. W. (1982): Ricinoleate and deoxycholate are calcium ionophores in jejunal brush border membrane vesicles. J. Membr. Biol., 70, 125-133. 
3) Maenz, D. D., and Forsyth, G. W. (1984): Calcium ionophore activity of intestinal secretory compounds an in vivo porcine model for the effects of bile acids hydroxy-fatty acids and dioctyl sulfosuccinate. Digestion, 30, 138-150.

4) Heaton, K. W. (1972): Bile Salts in Health and Disease, Churchill-Livingstone, Cambridge, UK.

5) Klaassen, C. D. (1974): Bile flow and composition during bile acid depletion and administration. Can. J. Physiol. Pharmacol. 52, 334-348.

6) Vonk, R. J., Van Doorn, A. B. D., and Strubbe, J. H. (1978): Bile secretion and bile composition in the freely moving, unanesthetized rat with a permanent biliary drainage: influence of food intake on bile flow. Clin. Sci. Mol. Med., 55, 253-259.

7) Coleman, R., and Holdsworth, G. (1976): The release of membrane components prior to haemolysis during extraction of intact erythrocytes with bile salts. Biochim. Biophys. Acta, 426, 776-780.

8) Vyvoda, O. S., Coleman, R., and Holdsworth, G. (1977): Effects of different bile salts upon the composition and morphology of a liver plasma membrane preparation: deoxycholate is more membrane damaging than cholate and its conjugates. Biochim. Biophys. Acta, 465, 68-76.

9) Coleman, R., Igbal, S., Godfoey, P. P., and Billington, D. (1979): Membranes and bile formation: composition of several mammalian biles and their membrane-damaging properties. Biochem. J., 178, 201-208.

10) Whelton, M. J., Kehayaglou, A. K., Agnew, J. E., Turnberg, L. A., and Sherlock, S. (1971): ${ }^{47}$ Calcium absorption in parenchymatous and biliary liver disease. Gut, 12, 978983.

11) Krawitt, E. L., Grundman, M. J., and Mawer, E. B. (1977): Absorption, hydroxylation and excretion of vitamin $\mathrm{D}_{3}$ in primary biliary cirrhosis. Lancet, 2, 1246-1249.

12) Compston, J. E., and Thompson, R. P. H. (1977): Intestinal absorption of 25-hydroxyvitamin D and osteomalacia in primary biliary cirrhosis. Lancet, 1, 721-724.

13) Herlong, H. F., Recker, R. R., and Maddrey, W. C. (1982): Bone disease in primary biliary cirrhosis: Histologic features and response to 25 -hydroxy-vitamin $\mathrm{D}$. Gastroenterology, 83, 103-108.

14) Matloff, D. S., Kaplan, M. N., Neer, R. M., Goldberg, M. J., Bitman, W., and Wolfe, H. J. (1982): Osteoporosis in primary biliary cirrhosis: Effects of 25-hydroxy-vitamin $\mathrm{D}_{3}$ treatment. Gastroenterology, 83, 97-102.

15) Bengoa, J. E., Sitrin, M. D., Meredith, S., Kelly, S. E., Shah, N., Baker, A. L., and Rosenburg, I. H. (1984): Intestinal calcium absorption and vitamin D status ị chronic cholestatic liver disease. Hepatology, 4, 261-265.

16) Kaplan, M. M., Goldberg, M. J., Matloff, D. S., Neer, R. M., and Goodman, D. B. P. (1981): Effect of 25-hydroxyvitamin $\mathrm{D}_{3}$ on vitamin $\mathrm{D}$ metabolites in primary biliary cirrhosis. Gastroenterology, 81, 681-685.

17) Turnberg, L. A., and Anthony-Mote, A. (1969): The quantitative determination of bile salts in bile using thin-layer chromatography and $3 \alpha$-hydroxysteroid dehydrogenase. Clin. Chim. Acta, 24, 253-259.

18) Krishnamra, N., and Boonpimol, P. (1986): Acute effect of ethanol on intestinal calcium transport. J. Nutr. Sci. Vitaminol., 32, 229-236.

19) Wasserman, R. H., Kallfelz, F. A., and Comar, C. L. (1961): Active transport of calcium by rat duodenum in vivo. Science, 133, 883-884.

20) Krawitt, E. L., and Schedl, H. P. (1968): In vivo calcium transport by rat small intestine. Am. J. Physiol., 214, 232-236. 
21) Krishnamra, N., and Limlomwongse, L. (1987): The in vivo effect of ethanol on gastrointestinal motility and gastrointestinal handling of calcium in rats. J. Nutr. Sci. Vitaminol., 33, 89-98.

22) Dumont, P. A., Curran, P. F., and Solomon, A. K. (1960): Calcium and strontium in rat small intestine: their fluxes and their effect on Na flux. J. Gen. Physiol., 43, 11191136.

23) Marcus, C. S., and Lengemann, F. W. (1962): Absorption of $\mathrm{Ca}^{45}$ and $\mathrm{Sr}^{85}$ from solid and liquid food at various levels of the alimentary tract of rat. J. Nutr., 77, 155-160.

24) Kurebe, M. (1978): Effect of deoxycholate on $\mathrm{Ca}^{2+}$-ATPase of intestinal brush border membrane. Biochem. Pharmacol., 27, 1961-1965.

25) Walling, M. W., and Kimberg, D. V. (1975): Active secretion of calcium, sodium and chloride by adult rat duodenum in vitro. Biochim. Biophys. Acta, 382, 213-217.

26) Walling, M. W., and Kimberg, D. V. (1973): Active secretion of calcium by adult rat ileum in vitro. Am. J. Physiol., 225, 415-422.

27) Nellans, H. N., and Kimberg, D. V. (1978): Cellular and paracellular calcium transport in rat ileum: effects of dietary calcium. Am. J. Physiol., 235, E726-E737.

28) Nellans, H. N., and Kimberg, D. V. (1979): Anomalous calcium secretion in rat ileum: role of paracellular pathway. Am. J. Physiol., 236, E473-E481.

29) Binder, H. J., Filburn, C., and Volpe, B. T. (1975): Bile salt alteration of colonic electrolyte transport: role of cyclic adenosine monophosphate. Gastroenterology, 68 , 503-508.

30) Chadwick, V. S., Carlson, G. L., Gaginella, T. S., Debongnie, J. C., Phillips, S. F., and Hoffman, A. F. (1977): Structure-activity relationships of bile acids in the rabbit colon. (Abstract), Eur. J. Clin. Invest., 7, 241-242.

31) Goer, K. L., Gross, M., Nell, G., Rummel, W., and Schulz, L. (1980): Comparative study of the effect of cholera toxin and sodium deoxycholate on the paracellular permeability and on net fluid and electrolyte transfer in the rat colon. Arch. Pharmacol., 312, 91-97. 